\title{
O ensino de língua portuguesa e os gêneros do discurso: uma proposta para a escola básica
}

\section{Portuguese language teaching and the discourse genres: a proposition for the basic school}

\author{
Fernanda Taís Brignol Guimarães ${ }^{1}$ \\ Matheus Felipe da Silva ${ }^{2}$ \\ Rafael Chaves Martins ${ }^{3}$
}

DOI: $10.28998 / 2317-9945.2019$ n63p7-22

\section{Resumo}

Este artigo resulta da oficina intitulada Gêneros do Discurso e Ensino: da teoria à prática, aplicada por pós-graduandos do Centro Universitário Ritter dos Reis - UniRitter - Porto Alegre/RS, com professores da rede pública, como parte do projeto de extensão Sexta-feira do Professor. A oficina teve como principal objetivo oportunizar aos docentes a reflexão a respeito dos gêneros discursivos por um viés prático, tendo em vista a recomendação dos Parâmetros Curriculares Nacionais para o estudo dos gêneros na escola. Desse modo, buscou-se suprir possiveis lacunas el ou dúvidas dos docentes a respeito do que são os gêneros discursivos e de como desenvolver atividades significativas a partir deles junto ao alunado, de modo a considerar a relação de interlocução estabelecida e o contexto de produção, recepção e circulação, conforme proposto por Bakbtin. A metodologia utilizada teve como base o Elevator Pitch ou Conversa de Elevador, proposta advinda da área empresarial, em que se objetiva vender uma ideia ou produto de forma sucinta e objetiva. Como resultados, pode-se dizer que a oficina atingiu seu objetivo, alinhando o engajamento dos docentes na atividade proposta e no debate suscitado à reflexão a respeito do estudo dos gêneros na escola e das adaptações necessárias a cada contexto de atuação.

Palavras-chave: Ensino de Lingua Portuguesa. Escola Básica. Parâmetros Curriculares Nacionais. Gêneros do Discurso. Elevator Pitch ou Conversa de Elevador

\begin{abstract}
This article is the result of a workshop for public school teachers entitled Genres of Discourse and Teaching: from theory to practice, applied by post-graduate students from the Centro Universitário Ritter dos Reis - UniRitter - Porto Alegre/RS, as part of the extension project Sexta-feira do Professor (Teacher's Friday). The main objective of the workshop was to provide teachers with a reflection on the discursive genres from a practical perspective, in resonance with the recommendation of National Curricular Parameters regarding the study of genres at school. In this way, we sought to fill in possible gaps and/or doubts of teachers regarding what are the discursive genres and how to work with them in order to develop meaningful activities for the students, taking into consideration the established interlocution relationship and the production context, reception and circulation, as proposed by Bakbtin.
\end{abstract}

\footnotetext{
1 Doutoranda em Letras pelo Programa de Pós-graduação em Letras Associação Ampla/Centro Universitário Ritter dos Reis. Mestra em Letras/Linguística Aplicada pela Universidade Católica de Pelotas.

${ }^{2}$ Mestrando em Linguística e especialista em Comunicação Empresarial pelo Centro Universitário Ritter dos Reis. Professor do Centro Universitário Ritter dos Reis.

${ }_{3}$ Mestrando em Letras do Centro Universitário Ritter dos Reis. Especialista em Assessoria Linguística e Revisão Textual na Faculdade Porto-Alegrense.
} 
The methodology used was based on the Elevator Pitch, proposed from the business area, which aims to sell an idea or product in a succinct and objective way. As a result, it can be said that the workshop achieved its objective, aligning the teachers' engagement with the proposed activity and the debate concerning the reflection on the study of the genres at school and the adaptations necessary to each context of action.

Keywords: Teaching Portuguese Language. Basic school. National Curricular Parameters. Discourse Genres. Elevator Pitch

Recebido em: 29/12/2018.

Aceito em: 16/02/2019.

\section{Introdução}

O ensino de Língua Portuguesa na escola vem passando por importantes transformações ao longo das últimas décadas. Com o avanço dos estudos linguísticos e com o surgimento de disciplinas voltadas para a investigação de fenômenos provenientes da língua em uso, como a sociolinguística, a pragmática, os estudos discursivos, as teorias modernas do letramento, dentre outros, a interação passou a assumir importante papel nos processos de investigação sobre língua, linguagem e ensino. A mera aquisição do código linguístico, antes visto como um processo puramente cognitivo e neutro, no âmbito da pedagogia tradicional, começa a dar espaço para discussões pautadas em teorias sociointeracionistas, discursivas e da enunciação, as quais situam a língua de acordo com o contexto específico de atividade. Por pedagogia tradicional, podem-se considerar os métodos de ensino pautados no autoritarismo, em que o professor é o centro do processo e a ele cabe a transmissão do conhecimento pronto e acabado, que deve ser assimilado pelos alunos, os quais são vistos como sujeitos esvaziados de saberes, um ensino, assim, pouco dialógico.

Nesse sentido, a prática pedagógica baseada em uma perspectiva interacionista distancia-se tanto do ensino tradicional, em que se tem por base o estudo da gramática normativa e que, por conseguinte, a partir das concepções de certo e errado, acaba-se por legitimar a modalidade padrão da língua como a única aceitável; quanto do ensino baseado no estruturalismo, que toma a língua como instrumento de comunicação, a qual passa a ser vista como um sistema e o que prevalece é o estudo de sua estrutura. Na perspectiva interacionista, tem-se por objetivo o contato com a linguagem a partir da participação dos sujeitos nas diferentes práticas sociais, por meio das quais os letramentos são adquiridos. Essa é, inclusive, a concepção que assumem os Parâmetros Curriculares Nacionais - PCN (BRASIL, 1998), em que se recomenda que o ensino de língua e linguagem privilegie o estudo dos gêneros textuais/discursivos ${ }^{4}$. Desse modo, o documento aponta para um trabalho que envolva os usos reais da linguagem nas mais variadas formas de interação entre os sujeitos, por meio do contato dos estudantes com textos autênticos e com a

\footnotetext{
${ }^{4}$ Neste estudo, tomamos por base a concepção de gêneros do discurso ou gêneros discursivos, provenientes da Análise dialógica da linguagem, de Mikhail Bakhtin. No entanto, nos PCN não há uma distinção clara entre esse conceito e o conceito de gêneros textuais, que advém da Teoria do Texto ou Linguística Textual, motivo pelo qual essa última nomenclatura foi mantida aqui, conforme utilizada pelos documentos oficiais que regem o ensino.
} 
diversidade de gêneros em que esses textos se organizam, mediante as diferentes esferas de uso da linguagem oral e escrita e das estratégias de organização textual-discursiva que esses gêneros envolvem, sem perder de vista seu contexto de produção, circulação e recepção.

O problema é que, muitas vezes, essas recomendações chegam para o professor que atua em sala de aula, seja por meio do livro didático - que em sua maior parte seguem a organização proposta nas orientações curriculares oficiais para o estudo do texto e do gênero nas aulas de língua e linguagem - ou mesmo por orientações pedagógicas da própria escola, sem que ele tenha sido preparado para desenvolver tal proposta junto ao alunado. Muitos desses professores, graduados já há algum tempo, nunca tiveram contato com teorias de gênero durante seus cursos de formação, e, mesmo dentre aqueles graduados recentemente, são poucos os que tiveram a oportunidade de estudar ou trabalhar com gêneros ao longo de sua formação, o que acaba gerando muitas dúvidas, incertezas e anseios na hora de aplicar esse tipo de proposta com seus alunos.

Dessa forma, diante da necessidade de contribuir para a formação do professor que deseja trabalhar com os gêneros do discurso em sala de aula, discutem-se, neste artigo, os resultados da oficina intitulada Gêneros do Discurso e Ensino: da teoria à prática, desenvolvida por pós-graduandos do Centro Universitário Ritter dos Reis - UniRitter - Porto Alegre/RS, como parte do projeto de extensão Sexta-feira do Professor, uma parceria do Núcleo de Extensão Universitária (ProAcad UniRitter), Secretaria da Educação (SEDUC), Instituto Estadual do Livro (IEL), e Comitê do Proler, que visa oferecer formação continuada a professores da Rede Pública de Ensino. Nesse sentido, a oficina teve como objetivo aplicar uma proposta de atividade com os professores envolvendo os gêneros do discurso, que pudesse ser reproduzida em sala de aula com seus alunos, atentando para as adequações necessárias. As questões teóricas, portanto, foram abordadas de forma mais geral, visto que o enfoque principal recaía na atividade prática, como um exemplo a ser desenvolvido pelos professores em suas escolas posteriormente.

Neste artigo, o leitor encontrará quatro seções, além desta introdução e das considerações finais e referências. Na próxima seção discute-se, de forma mais abrangente, os principais avanços do ensino de língua portuguesa nas últimas décadas, o que culminou na inclusão do estudo dos gêneros nas propostas de ensino de Língua Portuguesa para a escola básica, regulamentadas pelas Diretrizes Curriculares Nacionais. Na sequência, faz-se um apanhado teórico a respeito da concepção dialógica da linguagem de Mikhail Bakhtin, situando-se o conceito de gêneros do discurso, o qual serviu de base para o desenvolvimento da oficina ora apresentada. A seção que segue apresenta a metodologia do trabalho proposto, que tem como base o Elevator Pitch ou Conversa de Elevador, método originado no meio empresarial, cujo objetivo é convencer o interlocutor sobre a venda de determinada ideia ou produto de forma sucinta e objetiva. Após a apresentação da metodologia, descreve-se como ocorreu a aplicação da oficina juntamente com os professores e empreende-se a discussão dos resultados.

\section{O ensino de língua portuguesa na escola básica: principais avanços}

A sala de aula tem sido alvo de investigação já há algum tempo, o que tem resultado em inúmeros avanços teórico-metodológicos e de adaptação curricular. Muito dessas mudanças e avanços se deve à democratização do ensino, que torna a escola um espaço de convívio com a diversidade. O perfil homogêneo dos alunos de outrora, os quais possuíam 
alto nível de letramento, por fazerem parte das classes sociais mais prestigiadas, vem se apresentando como cada vez mais diversificado e híbrido, tanto no que tange a aspectos culturais quanto linguísticos. Já faz algum tempo que a escola deixou de ser um privilégio das camadas sociais dominantes, tornando-se lugar de convívio de um público bastante diversificado. Para dar conta desse novo perfil de aluno que chega à escola atualmente, proveniente das mais diversas camadas sociais, muito do que se tinha arraigado nos currículos escolares precisou ser revisto, a fim de atender a necessidades específicas desse novo alunado. No âmago das investigações sobre os processos de ensino-aprendizagem, passam a assumir fundamental importância as pesquisas sobre o uso situado da linguagem nos diversos contextos sociais. Assim, os estudos a respeito da interação, enunciação, variação linguística, dos letramentos como usos específicos da leitura e da escrita etc., tornam-se centrais para o entendimento a respeito do ensino-aprendizagem de língua e linguagem.

Nesse cenário, a visão da língua como fenômeno homogêneo e estático deixa de fazer sentido. Percebe-se que a variedade padrão da língua não deve ser a única forma legitimada pela escola, mas que, ao contrário disso, se faz necessário abandonar a noção de erro que se vinculava até então àqueles que não a utilizavam por fazerem parte das camadas sociais desprestigiadas. O fato de a escola passar a reconhecer as diferentes formas de linguagem utilizadas pelos alunos, sem deixar de lado, claro, o objetivo de apresentar-lhes a modalidade mais prestigiada, traz à tona uma nova forma de se conceber o ensino. Desse modo, os velhos exercícios de gramática, ou o estudo do texto descontextualizado, em que o aluno escreve apenas para a correção do professor, na forma da tão conhecida redação escolar, têm sido alvo de crítica por parte de muitos pesquisadores e estudiosos da linguagem.

De acordo com esses teóricos, por ser a língua um organismo vivo e dinâmico, não faz sentido tomá-la de forma estática, como muitas vezes ocorre na escola, em que os alunos são levados a realizar atividades pouco significativas envolvendo a decodificação e repetição de frases soltas, desvinculadas de um contexto real de enunciação, o que, por conseguinte, desconsidera a relação de interlocução constituinte de todo ato discursivo. A esse respeito, segue o que dizem os Parâmetros Curriculares Nacionais de Língua Portuguesa - PCN:

A importância e o valor dos usos da linguagem são determinados historicamente segundo as demandas sociais de cada momento. Atualmente, exigem-se níveis de leitura e de escrita diferentes dos que satisfizeram as demandas sociais até há bem pouco tempo - e tudo indica que essa exigência tende a ser crescente. A necessidade de atender a essa demanda, obriga à revisão substantiva dos métodos de ensino e à constituição de práticas que possibilitem ao aluno ampliar sua competência discursiva na interlocução.

Nessa perspectiva, não é possível tomar como unidades básicas do processo de ensino as que decorrem de uma análise de estratos letras/fonemas, sílabas, palavras, sintagmas, frases - que, descontextualizados, são normalmente tomados como exemplos de estudo gramatical e pouco têm a ver com a competência discursiva. Dentro desse marco, a unidade básica do ensino só pode ser o texto (BRASIL, 1998, p. 23).

E sendo o texto a realização material do discurso, não há texto sem assinatura, ou seja, não há texto que não seja de alguém e que, do mesmo modo, não se dirija a outro alguém. A relação de interlocução é fundamental, nesse sentido, pois é essa relação, entre 
os interlocutores, o que irá possibilitar que haja a valoração, condição própria de todo enunciado efetivamente produzido. Em outras palavras, é o tipo de interlocutor que irá guiar a construção do dizer. Quando se fala ao médico, ao professor, aos colegas, ou ainda, a amigos e familiares, não se faz da mesma forma, tanto a linguagem empregada como a forma que assume será necessariamente outra a depender da pessoa a que o discurso se dirige e da posição que ela ocupa, envolvendo maior ou menor proximidade com seu locutor. Assim sendo, os médicos, professores ou amigos também não ocupam a mesma posição, pode-se ter uma relação mais próxima com determinado médico do que com outro, por exemplo. Pode-se ter uma relação de amizade com determinado professor. Porém, o contexto de sala de aula ou não, de consulta ou não, também irá alterar o discurso, ainda que se trate de uma pessoa com quem se tem uma relação mais próxima. Todos esses são aspectos que determinam tanto a escolha do gênero quanto a forma discursivo-material por ele assumida.

Desse modo, não faz sentido solicitar ao aluno o simples preenchimento de lacunas, a repetição e decodificação das formas da língua ou a escrita estrutural de uma redação escolar, que não prevê uma situação específica e real de uso da língua. Como forma, portanto, de garantir um ensino significativo e contextualizado, que leve em consideração os usos reais da linguagem pelos sujeitos social e historicamente situados, é que surge a recomendação dos Parâmetros Curriculares Nacionais - PCN para que o ensino de Língua Portuguesa privilegie o contato com os gêneros do discurso, tendo o texto como unidade de ensino.

\begin{abstract}
Os textos organizam-se sempre dentro de certas restrições de natureza temática, composicional e estilística, que os caracterizam como pertencentes a este ou aquele gênero. Desse modo, a noção de gênero, constitutiva do texto, precisa ser tomada como objeto de ensino.

Nessa perspectiva, necessário contemplar, nas atividades de ensino, a diversidade de textos e gêneros, e não apenas em função de sua relevância social, mas também pelo fato de que textos pertencentes a diferentes gêneros são organizados de diferentes formas. A compreensão oral e escrita, bem como a produção oral e escrita de textos pertencentes a diversos gêneros, supõem o desenvolvimento de diversas capacidades que devem ser enfocadas nas situações de ensino. É preciso abandonar a crença na existência de um gênero prototípico que permitiria ensinar todos os gêneros em circulação social (BRASIL, 1998, p. 23-24).
\end{abstract}

A centralidade do texto em sala de aula e a noção da diversidade de gêneros que os organiza - como enunciados concretos, responsáveis pela veiculação de determinado discurso na sociedade - passam a ser tomadas como objeto de ensino nas escolas, além de figurar na elaboração de grande parte dos materiais didáticos, que buscam atender às orientações oficiais, já que, conforme argumenta Costa (2017),

Os Parâmetros Curriculares Nacionais de Língua Portuguesa (BRASIL, 1998) são um documento basilar não só para o ensino de Língua Portuguesa nas escolas brasileiras de Ensino Fundamental, como também para a elaboração das matrizes de referências da prova Brasil/SAEB, transformando-se, consequentemente, num texto guia e norteador das propostas de livros didáticos de Língua Portuguesa em nosso país (COSTA, 2017, p. 57).

Embora pareça não haver distinção na redação dos PCN a respeito das diferentes concepções de gênero existentes - textual e discursiva - o que pode ser percebido pelo uso no documento do conceito de gêneros textuais, ligado ao estudo do texto, em 
concomitância com a discussão sobre elementos da concepção dialógica da linguagem; considera-se, neste estudo, o acionamento de implicações teórico-metodológicas bastante diversas resultantes dessas diferentes concepções teóricas. Estando o primeiro caso voltado para concepções mais estruturais do gênero, preocupadas mais no sentido do estudo das formas textuais, as quais para a concepção discursiva de Bakhtin, base desta investigação, são as responsáveis pela realização material do discurso e não pelo gênero em si. $\mathrm{Na}$ concepção de Bakhtin o gênero é tomado para além do texto, já que irá depender das relações de interlocução e do projeto enunciativo do locutor, o que, por sua vez, irá determinar a forma composicional e a construção arquitetônica do dizer, conforme será debatido na próxima seção.

\section{A concepção dialógica de Bakhtin e os gêneros do discurso}

Bakhtin vê a língua como um fenômeno vivo e dinâmico, que serve à interação entre os sujeitos em contextos específicos de enunciação. Nesse sentido, existem modos específicos de enunciados, que se organizam e se moldam a partir de objetivos enunciativos específicos entre interlocutores específicos, em termos de determinados papéis sociais por eles assumidos. A esses modos específicos de interação, o filósofo russo denomina gêneros do discurso. Os gêneros do discurso são, portanto, "modos de interlocução" (SOBRAL; GIACOMELLI, 2016, p. 48) mais ou menos estáveis, que nascem das relações dialógicas da língua e a organizam em termos das esferas de atividade. Os sujeitos entram em contato com os gêneros e se apropriam deles ao participarem dessas diferentes esferas: familiar, escolar, jornalística, publicitária, dentre outras.

É importante ressaltar que existem gêneros mais e menos complexos, os quais Bakhtin chama de gêneros primários e secundários. Os gêneros primários fazem parte de esferas cotidianas e, portanto, entram para o repertório do falante de forma mais natural, por meio de sua participação em esferas familiares. Esse é o caso da conversa entre amigos ou pessoas da família, bilhetes, listas de compras, cartas pessoais, etc. Já os gêneros secundários são aqueles mais elaborados, pertencentes a esferas específicas, como a esfera jurídica, acadêmica, literária, entre outras. Para se apropriar desses últimos, faz-se necessária a participação dos sujeitos nessas esferas específicas. Em outras palavras, se for solicitado a alguém que prepare a defesa de um réu, dificilmente a tarefa será atendida, a menos que a pessoa a quem tal tarefa foi solicitada faça parte do meio jurídico, como um advogado, por exemplo.

Os gêneros, portanto, consistem em modos de interação no âmbito das diferentes esferas de uso da linguagem. Porém, eles não são estáticos, mas se alteram de acordo com os objetivos da enunciação. Bakhtin os concebe como "tipos relativamente estáveis de enunciados" (BAKHTIN, 2011, p. 262, grifo do autor), o que significa dizer que eles possuem elementos estáveis que permitem que sejam reconhecidos e mobilizados adequadamente em cada situação enunciativa, já que servem à interação de uma dada coletividade; mas é a partir do relativamente do gênero que ele se adapta e se reorganiza mediante as diferentes situações de interação. De acordo com Bakhtin,

Os gêneros do discurso organizam o nosso discurso quase da mesma forma que o organizam as formas gramaticais (sintáticas). Nós aprendemos a moldar o nosso discurso em formas de gênero e, quando ouvimos o discurso alheio, já adivinhamos o seu gênero pelas primeiras palavras, adivinhamos um determinado volume (isto é, uma extensão aproximada do conjunto do discurso), uma determinada construção 
composicional, prevemos o fim, isto é, desde o início temos a sensação do conjunto do discurso que em seguida apenas se diferencia no processo da fala. Se os gêneros do discurso não existissem e nós não os dominássemos, se tivéssemos de criá-los pela primeira vez no processo do discurso, de construir livremente e pela primeira vez cada enunciado, a comunicação discursiva seria quase impossível (BAKHTIN, 2011, p. 283).

Seria praticamente impossível criar um gênero a cada vez que se pretende comunicar em determinada esfera, para isso há um repertório infinito de gêneros que servem às mais variadas formas de interação. Porém, isso não significa que o gênero é fixo, muito pelo contrário, ele varia de acordo com os objetivos do discurso, mediante seu contexto de produção, circulação e recepção, que prevê a avaliação e participação ativa do interlocutor a quem o discurso se dirige. De acordo com Bakhtin,

A riqueza e a diversidade dos gêneros são infinitas porque são inesgotáveis as possibilidades da multiforme atividade humana e porque em cada campo dessa atividade é integral o repertório de gêneros do discurso, que cresce e se diferencia à medida que se desenvolve e se complexifica um determinado campo (BAKHTIN, 2011, p. 262).

Desse modo, os gêneros se reorganizam e se adaptam de acordo com as necessidades enunciativas dos sujeitos, podendo até mesmo dar origem a outros gêneros. Como exemplo disso, tem-se o e-mail, que surgiu como uma variante da carta, para suprir as necessidades enunciativas do meio digital, mas nem por isso também a carta deixou de existir em seus mais variados gêneros, a depender do objetivo enunciativo ou projeto enunciativo que realiza: carta de apresentação, carta de demissão, carta de solicitação, dentre outras tantas formas existentes (ARAÚUJO, 2006, p. 71).

Os gêneros compõem-se de três elementos indissociáveis, a forma composicional, o tema e o estilo. Além desses, há ainda a forma arquitetônica, que está na base de sua construção e diz respeito à relação existente entre autor, ouvinte e tópico. De acordo com Sobral (2009, p. 69), "A forma composicional se vincula com as formas da língua e com as estruturas textuais; a forma arquitetônica se vincula com o projeto enunciativo do autor, com o tipo de relação com o interlocutor que ele propõe". Desse modo, "a forma arquitetônica determina a forma de composição, mas esta nunca pode determinar a forma arquitetônica", pois ela liga-se à superfície discursiva, é a organização do discurso, sobre a qual "a atividade do autor incide primordialmente".

O tema não se confunde com o tópico ou assunto, mas consiste em "novos sentidos, que dependem dos contextos de uso". Trata-se do "sentido concreto, contextual, sentido que parte do sentido abstrato, registrado nos dicionários, e vai além dele" (SOBRAL, 2009, p. 74). Dito de outra forma, o tema é aquilo que o gênero realiza em dada enunciação. E, por fim, o estilo, em termos bakhtinianos,

[...] também é interativo, também é dialógico, vem da relação entre o autor e o grupo social de que faz parte, em seu representante autorizado, ou típico, a imagem social do ouvinte, que também é um fator intrínseco vital da obra. O estilo tem relações com a forma do conteúdo, o modo como o conteúdo é organizado, e não tem a ver com um "desvio" da norma, do mesmo modo como seu uso não se restringe à obra literária (SOBRAL, 2009, p. 64, grifo do autor). 
A partir daí, percebe-se que os gêneros do discurso, de Mikhail Bakhtin, vão muito além do texto, que os realiza materialmente, pois envolvem a interrelação de todos esses elementos que os compõem, mediante dada situação enunciativa, e, de acordo com os objetivos e os papéis dos interlocutores, em termos das esferas de atividade. Assim, não basta olhar apenas para a forma textual do gênero, já que são os elementos discursivos e o projeto enunciativo do locutor que os definem, mediante avaliação e participação ativa dos interlocutores do discurso. Nas palavras de Sobral,

[...] o texto é, ao mesmo tempo, o aspecto mais importante e o menos importante da criação de sentidos: o mais importante porque, sem sua materialidade, não pode haver produção de sentidos; o menos importante porque, tomado isoladamente, apresenta potenciais de significação que somente quando são mobilizados pelo discurso, no âmbito do gênero, criam sentido (SOBRAL, 2008, p. 2).

Assim, um ensino significativo de língua portuguesa via gêneros discursivos na escola implica em desenvolver um trabalho com gêneros do discurso que vá além da análise puramente textual, mas que envolva situações reais de interação, a partir de objetivos específicos, em termos do contexto de produção, circulação e recepção do gênero. Dessa forma, o aluno terá contato com os usos reais da linguagem e não apenas com exercícios de classificação a respeito dos tipos textuais existentes, até porque essa seria uma tarefa exaustiva e não faria sentido algum, visto que as formas de textos são inesgotáveis e não existem por si só, mas sempre no âmbito de algum gênero.

Após essa breve contextualização sobre o conceito bakhtiniano de gêneros do discurso, apresenta-se, na seção seguinte, a metodologia que serviu como base para a aplicação da proposta prática com os docentes da escola básica, isto é, o Elevator Pitch ou Conversa de Elevador.

\section{O Elevator pitch ou Conversa de Elevador}

O Elevator pitch é uma técnica desenvolvida na área de negócios empresariais e do empreendedorismo. Pitch significa a apresentação rápida de uma ideia ou oportunidade de um negócio e a palavra elevator, traduzida para o português, é elevador. No Brasil, a expressão americana foi adaptada e ficou conhecida como Conversa de Elevador. A metodologia foi criada partindo da ideia da oportunidade de venda de um projeto a determinado investidor, por meio de um encontro no elevador. Os poucos segundos até os andares escolhidos, portanto, são determinantes para a apresentação de uma parceria de negócios. Por isso, há a necessidade de se construir um discurso com argumentos claros, sucintos e objetivos, que alie agilidade e precisão na informação.

Desse modo, o Pitch tem o objetivo de formular uma apresentação sucinta e eficiente, fazendo com que a exposição transmita uma mensagem profunda, direta, e que convença o público (interlocutor) desejado. Muitas estratégias são usadas e adaptadas de acordo com a necessidade do locutor. Gray et al. (2010, p. 23) sugerem a necessidade de se criar um roteiro lógico que seja balizado pelos objetivos pretendidos: "Quem é o públicoalvo?”; "Qual é a necessidade do cliente?"; "Qual é o nome do produto/serviço?”; "Para qual categoria de mercado?"; "Qual é o seu principal benefício?”; "Quem ou o que é a concorrência?”; "Qual é o diferencial do produto?”. 
Como uma oficina, normalmente, precisa ter caráter muito mais prático do que teórico, e essa metodologia pareceu um bom exemplo a ser utilizado em uma atividade que tenha por base as propostas discursivas de gêneros, uma vez que gera no locutor a necessidade de situar sua proposta, por meio das questões acima expostas, considerou-se a técnica do Pitch como uma boa oportunidade de mostrar aos docentes um exemplo de trabalho com os gêneros para além de suas formas textuais e de estrutura, mas sim, considerando o interlocutor real ou presumido e a situação de enunciação específica. Algumas adaptações foram feitas para a adequação da metodologia de acordo com a proposta da oficina.

A partir do tópico $O$ uso de celular em sala de aula, sugerido pelos acadêmicos oficineiros, os professores foram desafiados a pensar em alternativas para resolver a situação que se desenhava em cada instituição de ensino em específico, cabendo a eles a escolha por defender ou não o uso do aparelho como instrumento pedagógico, de acordo com o que mais se adequaria à política educacional de cada contexto de atuação. Os docentes foram divididos em grupos e cada grupo teve 15 minutos para elaborar sua apresentação, visando seu interlocutor específico, neste caso, a coordenação pedagógica e/ou direção da escola. Na sequência, foi eleito um representante de cada equipe, o qual teria três minutos para anunciar as ideias e tentar convencer seu interlocutor. O papel dos gestores escolares ficou a cargo dos acadêmicos, que propuseram a dinâmica. Apenas uma apresentação sairia vencedora do desafio.

\section{Aplicação da oficina e discussão dos resultados}

A oficina realizada proporcionou aos professores o trabalho com os gêneros do discurso pelo viés prático. Primeiramente, contextualizou-se o conceito de gênero na obra de Bakhtin, promovendo uma reflexão a respeito da distinção entre os conceitos de gêneros textuais e gêneros do discurso e as implicações teórico-metodológicas advindas da escolha por um ou outro conceito. A discussão levou à reflexão a respeito do tratamento estrutural dado ao gênero em muitos materiais didáticos organizados pelo viés do estudo do texto, e, até mesmo, presente nas Diretrizes Curriculares Nacionais, que alinham a teoria dialógica de Bakhtin a teóricos da Linguística Textual, motivo pelo qual se percebe no documento a concomitância entre o uso do termo gênero textual, advindo da Linguística textual ou Teoria do texto e a menção de elementos da concepção discursiva de Bakhtin. A falta de clareza a respeito dos diferentes vieses de estudo do gênero e, por conseguinte, das diferentes implicações teórico-metodológicas aí envolvidas, se reflete no discurso dos professores, para os quais, muitas vezes, permanece a dúvida a respeito desses diferentes conceitos, isto é, gênero textual/gênero discursivo. O excerto 1, a seguir, revela a reflexão de uma das professoras participantes da oficina a esse respeito, a qual será designada aqui como participante $A^{5}$ :

\section{Excerto 1: fala da participante A.}

Essa é uma dúvida que eu tenho, sobre a diferença entre gêneros textuais e gêneros do discurso. Porque se for ver nos livros didáticos e até mesmo nos PCN, como vocês disseram, o mais utilizado é gênero textual, né? De que modo deve ser o trabalho com gêneros, então?

Fonte: debate realizado durante a oficina.

\footnotetext{
${ }^{5}$ Por motivos éticos, a identidade dos professores será preservada, substituindo-se seus nomes pelo termo "participante", seguido das letras A, B, C e D.
} 
A fala da participante A revela certa inquietação com relação ao que estava sendo debatido na oficina, que, de certo modo, parece ter desconstruído o que ela acreditava ser a forma mais adequada de estudo do gênero, o que se confirma pelo argumento de autoridade por ela utilizado ao mencionar as orientações dos livros didáticos e dos PCN: "Se for ver nos livros didáticos e (...) nos PCN, (...) o mais utilizado é gênero textual, né?". Esse argumento é reforçado ainda pela pergunta feita a seguir: "De que modo deve ser o trabalho com gêneros, então?". Esse enunciado poderia ser reelaborado da seguinte forma: "mas se vocês afirmam que não há clareza nas orientações curriculares oficiais e nos livros didáticos a respeito do trabalho com os gêneros, como esse trabalho deve ser feito então?".

Nesse momento, outra professora (participante B) toma a palavra, complementando a reflexão da participante A, conforme o excerto 2:

Excerto 2: fala da participante B.

Eu costumo trabalhar com os gêneros textuais nas minhas aulas e também com projetos, que são bastante incentivados na escola em que trabalho. Nos livros didáticos, geralmente, vêm atividades a partir de receitas, HQ's, propagandas. Eu procuro trazer esses gêneros para os alunos.

Fonte: debate realizado durante a oficina.

Note-se que a participante B tenta responder ao questionamento feito por A, indicando atividades a partir de diferentes gêneros presentes nos livros didáticos, bem como a realização de projetos em sua escola. Essa afirmação revela-se bastante pertinente, motivando o debate a respeito da importância de uma pedagogia de projetos para a ressignificação da leitura e da escrita em sala de aula, que passam a envolver objetivos reais, na busca pela solução de problemas também reais. Nesse sentido, Oliveira (2010) vem corroborar a afirmação da participante $\mathrm{B}$, ao indicar em seu estudo os projetos de letramento como uma alternativa para o desenvolvimento de um trabalho contextualizado com os gêneros, já que, desse modo, os gêneros estarão inseridos em práticas sociais situadas e, por isso mesmo, envolverão inevitavelmente uma relação de interlocução, real ou presumida. Outros professores mencionaram os projetos como uma excelente alternativa para o trabalho contextualizado com a língua, os quais podem, inclusive, envolver atividades interdisciplinares.

O debate seguiu com destaque para o fato de que, nas orientações curriculares e, até mesmo em muitas pesquisas teóricas a respeito dos gêneros, é comum encontrar a discussão a respeito dos elementos que o compõem, tais como descrito por Bakhtin, isto é, a forma composicional, o tema e o estilo. No entanto, como já foi dito anteriormente, o que não se faz tão comum é a discussão a respeito do que Bakhtin definiu como a base de construção do gênero, isto é, sua construção arquitetônica, a qual decorre da relação de interlocução estabelecida. $\mathrm{Na}$ concepção dialógica, é somente em termos dessa relação que se pode definir o gênero, embora ele possa apresentar-se materialmente a partir de diferentes formas textuais. Essa é uma questão ainda pouco clara para muitos, o que acaba contribuindo para o estudo estrutural do gênero, que o toma como tipos de texto ou como modelos de estruturas fixas que podem ser aplicados indistintamente a depender do tipo de interação que se estabelece. Esclarecer essa questão, portanto, foi um dos grandes objetivos da oficina, que buscou mostrar, a partir da atividade prática, como a relação de interlocução é a grande responsável pela forma de organização do discurso, a qual permeia a avaliação e antecipação do dizer do outro.

Logo após o debate, então, buscou-se aliar o que havia sido discutido a respeito da teoria dialógica à proposta prática da oficina, momento em que os professores puderam 
perceber a importância de se ter bem claro qual é a situação enunciativa e quem são os interlocutores do discurso. Uma vez que os gêneros são modos de interlocução que organizam a linguagem e que a linguagem é viva e dinâmica, não faz sentido algum solicitar ao aluno, por exemplo, que utilize determinado gênero apenas como um modelo de texto, o qual ele deverá internalizar e repetir indistintamente. $O$ trabalho com gêneros exige que se tenha bem definida a situação real de enunciação, que envolve interlocutores reais ou presumidos.

Em outras palavras, solicitar a escrita de uma carta aleatoriamente, por exemplo, apenas esperando que o aluno utilize o vocativo, local e data, formas de despedida, conteúdos esses, geralmente, estudados nas aulas de português, não significa que se está trabalhando com o gênero carta, ou melhor, com os gêneros carta, já que, conforme já mencionado, não há apenas um gênero de carta, mas diferentes cartas, que servem a diferentes projetos enunciativos. Esse tipo de trabalho, a partir da estrutura do gênero, serve apenas à memorização e repetição de suas formas textuais, que o realiza materialmente, mas que não o determina, já que essas escolhas textuais são feitas sempre em termos da enunciação específica e dos participantes do discurso (GUIMARÃES, 2015).

Ainda em se tratando da carta, que vem sendo tomada como exemplo, o que não exclui os demais gêneros, a construção composicional e arquitetônica do dizer certamente não ocorrerá da mesma forma a depender do seu endereçamento. Uma carta escrita para a mãe, amigo ou namorado será totalmente diferente, tanto na forma quanto no conteúdo, de outra escrita para o chefe de departamento, colega de trabalho ou cliente da empresa. Cada situação específica de interlocução implica formas específicas de construção e estruturação do dizer. Em cada um dos casos mencionados estão envolvidos temas específicos, isto é, o que se deseja alcançar com o gênero varia em cada uma dessas situações, e isso implica no modo de organização do discurso. O gênero assume, portanto, uma construção arquitetônica autoral, a depender do tipo de interlocução estabelecido, o que, por conseguinte, irá determinar sua forma composicional.

Diante do exposto, o primeiro passo para encaminhamento da atividade prática da oficina foi o de criar uma situação de interlocução específica, a partir da qual os professores pudessem assumir a posição de locutores e dirigirem-se a interlocutores reais com objetivos também reais (ou o mais próximo possível da realidade, já que uma atividade didática envolverá sempre objetivos didáticos e de ensino). Assim, embora o gênero a ser utilizado fosse o mesmo, cada um daria o tom e a forma mais adequada a seu dizer de acordo com seus contextos reais e com o tipo de interlocutor envolvido no discurso.

Como já mencionado na seção metodológica deste estudo, a atividade prática proposta envolveu o Pitch ou Conversa de Elevador, originada no meio empresarial, e que, como o próprio nome sugere, trata-se de uma estratégia de venda de um produto ou ideia de forma sucinta e objetiva, já que a oportunidade de contato e convencimento do possível investidor acontece no curto espaço de tempo de uso do elevador. Então, o proponente deve usar de sua criatividade e poder de persuasão a fim de alcançar os objetivos da venda nesse curto espaço de tempo. Para a oficina, essa proposta precisou ser adaptada a fim de contemplar a realidade escolar. Percebeu-se que para envolver os professores no debate seria necessário lançar mão de um tópico de seu interesse, algo que fosse vivenciado por eles em seu dia a dia de trabalho. Dessa forma, os pós-graduandos sugeriram que se discutisse a respeito da polêmica do uso do celular na escola, temática que foi bastante aceita pelos docentes. 
A ideia era que os docentes pensassem em seus contextos escolares e a partir daí decidissem defender ou não o uso pedagógico do aparelho, utilizando-se da metodologia do Pitch, isto é, imaginando-se em um encontro com seus coordenadores e/ou diretores de escola em um elevador e tendo que defender seus projetos em um tempo estimado de apenas três minutos. Para tanto, apresentou-se a dinâmica a partir de um vídeo introdutório ${ }^{6}$, como forma de situar os docentes a respeito da atividade que deveria ser realizada com base nessa metodologia. $\mathrm{Na}$ sequência, a turma presente foi dividida em seis grupos de cinco ou seis pessoas e cada grupo recebeu a missão de elaborar um projeto em 15 minutos, a partir do tópico proposto: $O$ uso de celular em sala de aula.

O excerto 3, a seguir, apresenta a reflexão da participante $\mathrm{C}$ a respeito das dificuldades enfrentadas por seu grupo para desempenhar a tarefa solicitada, o que a fez pensar nas atividades propostas para os alunos na escola:

\section{Excerto 3: fala da participante C.}

A gente sentiu uma enorme dificuldade na realização dessa atividade. Muitas vezes, na escola, a gente quer que o aluno escreva e não se dá conta como a falta de contextualização pode ser um impeditivo real para a escrita. Aqui nós tínhamos o contexto, né, e mesmo assim não foi tão fácil.

Fonte: debate realizado durante a oficina.

A fala da professora revela um deslocamento da posição de docente para o lugar geralmente assumido pelo aluno em sala de aula. E, do lugar do outro, ela percebe a importância de se propor atividades com um significado real, ressaltando o fato de como a escrita somente para o professor pode vir a ser um dos grandes impedimentos para o sucesso escolar dos estudantes.

Dos seis grupos formados, quatro conseguiram finalizar a tarefa até a etapa de apresentação dos projetos de defesa ou não do uso do celular na escola, sendo que todos os projetos tiveram como base a defesa do uso pedagógico do celular em sala de aula. Um dos grupos que não conseguiu desenvolver a proposta era formado por docentes que atuam em uma Fundação de Atendimento Socioeducativo - FASE, local em que é proibida a entrada de celulares, inclusive por parte dos professores e funcionários. O que é extremamente significativo para o debate que vem sendo levantado neste estudo, pois revela a importância da situação real de enunciação na produção do gênero. No contexto educativo desses docentes não faria sentido algum defender ou condenar o uso do aparelho, uma vez que o não uso de celulares nesse tipo de instituição já é algo estabelecido e regulamentado pela legislação vigente. $\mathrm{Na}$ escola, muitas vezes, tende-se a solicitar aos alunos que escrevam aleatoriamente sobre algo, apenas com o objetivo da avaliação do professor, e, dessa forma, acaba-se por desconsiderar o fato de que uma atividade de escrita sem contextualização, sem endereçamento, sem um objetivo claro e bem definido pode ser algo extremamente difícil para os alunos, já que não envolve um sentido discursivo real.

Pela ótica dialógica do discurso, as palavras não são mencionadas ao acaso, " $\mathrm{Na}$ realidade, não são palavras o que pronunciamos ou escutamos, mas verdades ou mentiras, coisas boas ou más, importantes ou triviais, agradáveis ou desagradáveis, etc" (BAKHTIN/VOLOCHINOV, 2014, p. 98-99). Nesse sentido, o enunciado é sempre uma resposta ou antecipação do discurso de outrem, ele faz parte da rede socioideológica que constitui a linguagem. E sendo o gênero um "tipo relativamente estável de enunciado", ele

6 Vídeo que resume a técnica do Pitch, apresentado aos docentes. Disponível em: <https://www.youtube.com/watch?v=h3VUXtm8FVg>. Acesso em: 7 mar. 2019. 
não poderá ser tomado como uma categoria fixa, desconectada da realidade, sob a pena de estar-se trabalhando apenas a forma estrutural do dizer. Justamente por se tratar de uma situação real de enunciação é que esses docentes se sentiram impedidos de realizar a atividade, uma vez que a discussão sobre o uso do celular não se configura como possibilidade real em sua realidade de atuação.

Voltando à aplicação da oficina, encerrado o prazo de elaboração das propostas, os três oficineiros sentaram-se em frente à mesa. Um cronômetro foi projetado, contando o tempo de cada apresentação. Em sua maior parte, os participantes mostraram-se muito engajados no desenvolvimento da atividade e na defesa de seus projetos, alguns mais participativos do que outros, naturalmente. Todos os quatro grupos apresentaram suas propostas de defesa do uso pedagógico do celular em sala de aula dentro do tempo previsto. Cada escola teve sua demanda específica explicitada por um representante do grupo e, no geral, os argumentos apresentados em defesa dos projetos foram muito bem elaborados, de modo que a escolha do grupo vencedor não foi tarefa fácil para os oficineiros/avaliadores. O grupo ganhador, no entanto, embasou sua proposta na falta de uma biblioteca em sua escola, o que justificaria a necessidade de implementação do projeto de uso dos celulares em sala de aula, como forma de ampliar a oportunidade de leitura, pesquisa e de busca pela informação entre o alunado.

Como atividade de fechamento da oficina, discutiu-se o quanto as propostas apresentadas pelos grupos mantiveram algo em comum, já que partiam da mesma proposta metodológica, tendo, contudo, o seu diferencial na forma de construção do discurso e na apresentação de cada representante, o que resultou de cada situação enunciativa em específico - justamente o que se espera de um trabalho significativo com os gêneros do discurso em sala de aula. Houve um debate ao final da oficina, a partir do qual os participantes tiveram a oportunidade de expor as suas opiniões sobre a proposta de trabalho ora apresentada, refletindo sobre como seria a aplicação da atividade desenvolvida na oficina em seus contextos reais de atuação. Desse debate, optou-se pela seleção de duas falas, que, da perspectiva deste estudo, mostram-se como mais significativas. A primeira (excerto 4) consiste na fala da participante $A$, que retoma sua reflexão inicial, apontando para a construção de novos sentidos a respeito do trabalho com gêneros na escola, demonstrando ter superado a dúvida outrora apresentada:

Excerto 4: fala da participante A.

Um trabalho com o texto e com as regras da gramática, por exemplo, a partir do texto, pode trazer contribuições para a formação do aluno, mas se não tiver um objetivo e um sentido real não é gênero. Dá pra pensar em um trabalho de pesquisa envolvendo um determinado tema e, dentro desse tema, envolver o estudo dos gêneros: entrevista, resumo, debate... Isso pode, até mesmo, fazer parte de um projeto maior da turma ou da escola. Acho que assim contribuiria para um trabalho mais adequado com o gênero.

Fonte: debate realizado durante a oficina.

Já a segunda fala (excerto 5) demonstra a preocupação do participante D em buscar novos caminhos para o ensino de língua portuguesa na escola. $O$ professor ressalta a importância da formação continuada, apontando para a ideia de que, para além de o que fazer, é preciso compreender como fažer, o que nem sempre fica tão explícito nas recomendações dos documentos oficiais ou nos livros e materiais didáticos. 
Excerto 5: fala do participante D.

O discurso de inovação no ensino de língua portuguesa está presente em toda parte. A gente ouve que ensinar a gramática tradicional não faz mais sentido. Uma boa aula deve partir do texto. Os livros, atualmente, vêm com diversas atividades organizadas em torno do estudo do texto. Tem muito do o que fažer e pouco do como fažer. Eu considero esses momentos de formação de extrema importância para que o professor possa se atualizar e trocar ideias e experiências com colegas e demais profissionais da educação.

\section{Fonte: debate realizado durante a oficina.}

Os excertos revelam claro interesse por parte dos professores no desenvolvimento de um trabalho significativo com os gêneros na escola, o que, no entanto, pareceu não estar muito claro para eles é o modo mais adequado de realizar esse trabalho junto ao alunado, pensando na perspectiva discursiva e não apenas com vistas ao estudo da estrutura textual do gênero. Dúvida essa que parece ter sido suprida ao longo do desenvolvimento da oficina, pelo menos é o que revelam os dois últimos relados apresentados nos excertos $4 \mathrm{e}$ 5 , por meio dos quais os docentes expressam seu entendimento sobre a proposta da oficina e sobre como adaptá-la a seus contextos de trabalho, ou então, sobre como desenvolver outras propostas que, assim como essa, também envolvam um estudo contextualizado do gênero.

Acredita-se que essa oficina atingiu seu objetivo, tendo em vista que, além da participação na tarefa e no debate, houve a reflexão de cada um sobre a sua realidade em sala de aula, em como essa dinâmica seria aplicada ou como outras propostas melhor se adequariam à realidade específica de cada um. Porém, talvez o mais importante tenha sido a experiência proporcionada aos professores da rede pública de ensino, por meio da qual os docentes puderam refletir sobre o ensino de língua e sobre a necessidade de se trabalhar com a perspectiva dos gêneros do discurso em sala de aula, levando em consideração a relação de interlocução e o contexto real de produção, circulação e recepção do gênero.

\section{Considerações finais}

O avanço dos estudos linguísticos - que passam a dar ênfase a pesquisas voltadas para o funcionamento real da linguagem em contextos específicos de interação, a partir de pesquisas ligadas a disciplinas como a sociolinguística e a pragmática, ou os estudos sobre letramento, discurso e enunciação, por exemplo - acaba levando a alterações nas Diretrizes Curriculares Nacionais e, por conseguinte, nos currículos das escolas e na organização de materiais pedagógicos e livros didáticos. No entanto, nem sempre esses avanços chegam de forma clara ao professor que atua em sala de aula, o qual tem de adequar seu trabalho de acordo com essas novas orientações sem que, muitas vezes, disponha de suporte necessário para fazê-lo.

Um exemplo desse dilema recai justamente no trabalho com os gêneros textuais (advindos dos estudos do texto) ou discursivos (originados dos estudos dialógicos de Bakhtin), sobre os quais, conforme debatido neste estudo, não há um consenso bem definido nem mesmo entre teóricos da área, o que se reflete, inclusive, na redação dos PCN, que não difere entre os dois conceitos, ignorando as implicações teóricometodológicas que advém dessas duas concepções teóricas. Diante do exposto, a oficina ora discutida neste artigo teve como principal objetivo suprir possíveis dúvidas dos docentes da escola básica a respeito do trabalho com os gêneros do discurso, tomados pelo 
viés bakhtiniano, isto é, para além do texto que realiza materialmente o dizer, mas como modos de interlocução que organizam a linguagem mediante as esferas de atividade humana.

Dúvidas essas que parecem ter sido esclarecidas por meio do debate teórico aliado à prática desenvolvida na oficina, uma vez que os docentes demonstraram total engajamento na realização da atividade proposta e levantaram questões a respeito de sua possível aplicação em suas salas de aula, mediante adequações necessárias, visando sempre o estabelecimento de uma real situação de enunciação e não apenas trabalhando as formas textuais do gênero. Desse modo, os gêneros puderam ser pensados de acordo com o que define Bakhtin, isto é, sem que o real contexto de enunciação e a relação de interlocução sejam desconsiderados, sendo esta última a responsável pela valoração do dizer, o que, por sua vez, implica na organização e estruturação do discurso e na realização do gênero.

\section{Referências}

ARAÚJO, J. C. Os chats: uma constelação de gêneros na internet. 2006. Tese (Doutorado em Linguística) - Universidade Federal do Ceará, Fortaleza, 2006.

BAKHTIN, M. Estética da criação verbal. 6. ed. Tradução: Paulo Bezerra. São Paulo: Martins Fontes, 2011.

BAKHTIN, M./VOLOCHINOV, V. N. Marxismo e filosofia da linguagem: problemas fundamentais do método sociológico na ciência da linguagem. 16. ed. Tradução: Michel Lahud e Yara Frateschi Vieira. São Paulo: Hucitec, 2014.

BRASIL. Ministério da Educação. Secretaria de Educação Fundamental. Parâmetros Curriculares Nacionais - Língua Portuguesa $-5^{\mathrm{a}}$ à $8^{\mathrm{a}}$ série do ensino fundamental. Brasília: MEC/SEC, 1998.

COSTA, E. Um room na imagem: verbo-visualidade em livros didáticos. In: SILVA, A.; COSTA, E. (org.). Livro didático: olhares dialógicos. Campinas: Pontes, 2017.

GRAY, D.; BROWN, S.; MACANUFO, J. Gamestorming: a playbook for innovators, rulebreakers, and changemakers. Sebastopol: O'reilly, 2010.

GUIMARÃES, F. T. B. Uma análise dialógica do gênero acadêmico dissertação: estudo de caso. 2015. Dissertação (Mestrado em Letras/Linguística Aplicada) Universidade Católica de Pelotas, Pelotas, 2015.

OLIVEIRA, M. S. Gêneros textuais e letramento. Revista Brasileira de Linguística Aplicada, Belo Horizonte, v. 10, n. 2, p. 325-345, 2010.

SOBRAL, A. U. As relações entre texto, discurso e gênero: uma análise ilustrativa. Revista Intercâmbio, São Paulo, v. XVII, p. 1-14, 2008.

SOBRAL, A. U. Do dialogismo ao gênero: as bases do pensamento do círculo de Bakhtin. Campinas: Mercado de Letras, 2009. 
SOBRAL, A. U.; GIACOMELLI, K. Gêneros, marcas linguísticas e marcas enunciativas: uma análise discursiva. In: SOUZA, S.; SOBRAL, A. Gêneros, entre o texto e o discurso: questões conceituais e metodológicas. Campinas: Mercado de Letras, 2016. 